\title{
Developing Pre-service Science Teachers' Teaching Practices with an Emphasis on Higher Order Thinking
}

\author{
Akarat Tanak* \\ Department of Education, Faculty of Education, Kasetsart University, Bangkok, Thailand
}

*Corresponding Author: akarat.t@ku.th

\section{ABSTRACT}

Pre-service teachers face challenges in learning how to implement inquiry-based learning to enhance students' higher order thinking skills (HOTS) effectively. This study describes pre-service science teachers' instructional practices to teach HOTS related to key aspects of inquiry. The study group comprised 15 undergraduate pre-service teachers who enrolled in the thinking course of a 5-year teacher enhancement program. The pre-service teachers' lesson plans and teachers' self-reflections on their practices were collected, and then analyzed by descriptive statistics and inductive analysis. Findings indicated that the pre-service teachers were most likely first, to advance their level of inquiry; and second, to shift their teaching practices from focusing on science as a process to be learned about that primarily represents the inquiry features of only evidence and explanation to the inclusion of all five features of inquiry. Moreover, pre-service teachers were able to design creative and reasoning-enriched activities. They promoted the following aspects of inquiry: Asking divergent questions on a problematic situation, having students think originally for investigation, building and refining a model or design, and generate and test hypotheses reasonably leading to causal inferences. The findings from this methods course point toward future directions for effective courses that develop pre-service teachers' practices aimed to promote students' thinking skills.

KEY WORDS: inquiry; methods course; pre-service teachers; teaching practices; higher order thinking

\section{INTRODUCTION}

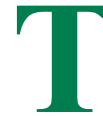

he challenges of our world resulting from scientific and technological advancements require students to develop their higher order thinking skills (HOTS), such as critical thinking, decision-making, and problemsolving skills (Miri et al., 2007). The development of HOTS is imperative to becoming a scientifically literate person able to make wise decisions and solve the complicated problems of the future (NRC, 2000). The National Science Education Standard (NSES) indicates that students should:

- Develop the ability to think and act in ways associated with inquiry, including asking questions, planning and conducting investigations, using appropriate tools and techniques to gather data, thinking critically and logically about relationships between evidence and explanations, constructing and analyzing alternative explanations, and communicating scientific arguments. (NRC, 1996. p. 105). Science educators have been challenged to develop an approach to help students become scientifically literate. Such reforms explicitly ask teachers to change their teaching strategies to focus on inquiry-based learning (Britner and Finson, 2005; Newman et al., 2004; Zohar and Dori, 2003).

Research has shown that inquiry-based learning can be effectively implemented to stimulate students' thinking skills (Marshall and Horton, 2011; Yager and Akcay, 2010). Inquirybased teaching allows students to participate in scientific investigations by making hypotheses, designing experimental procedures, and interpreting data and evidence, rather than focusing on learning content and concepts (Morrison, 2014). However, teachers regard inquiry processes as open processes during which students seek answers to their own questions by themselves, without involving questioning and thinking in the process (Kim and Chin, 2011). Therefore, students spend time collecting data or completing procedures, rather than engaging in discussions on analyzing data, generating conclusions, or synthesizing new findings with the previous ideas (Rod Watson et al., 2004).

Research indicates that preparing pre-service teachers to implement inquiry-based learning is even more challenging, as studies have revealed that pre-service science teachers have difficulty creating inquiry-based classroom environments to support students' development of thinking skills (Kim and Chin, 2011; Yoon et al., 2012). Most pre-service teachers fail to translate inquiry into classroom practice because of their own limited inquiry learning experiences (Ann Haefner and Zembal-Saul, 2004). Consequently, studies have reported various courses for preparing pre-service teachers that incorporate direct inquiry investigation experiences (e.g., Brown and Melear, 2006). Educators engaged teachers in open-inquiry projects and inquiry-based lessons to strengthen their beliefs about and increase their understanding of the nature of inquiry and to build their confidence for teaching inquiry science (Lee and Shea, 2016; Magee and Flessner, 
2012; Windschitl, 2003). However, limited research focuses on developing pre-service teachers' inquiry-based teaching practices (Britner and Finson, 2005), and empirical evidence on the effectiveness of courses/programs that support effective inquiry practices and emphasize thinking skills for pre-service teachers is limited. Crawford (2016), for example, addressed an effective professional development program to support teachers in enacting inquiry/science practices-based teaching with an emphasis on engaging students in critical thinking and using logic and evidence. However, prior studies have not clarified the interrelationship of the features of inquiry and thinking skills used as a framework to develop inquiry method courses; this is the process scientists apply in practice. The current study presents a science methods course to enhance pre-service teachers' ability to implement effective inquiry teaching practices that emphasized HOTS; this study further examined the impact of the course on teacher practices. The purpose of this study was to examine how an inquiry-based course develops pre-service science teachers' ability to teach HOTS related to key aspects of inquiry. The study is guided by the following questions:

1. What elements and levels of inquiry-based science teaching do pre-service teachers emphasize in designing learning activities?

2. What aspects of HOTS are promoted by pre-service teachers?

\section{Conceptual Framework}

\section{Higher order thinking}

Teaching science by inquiry is a complex task that requires higher-order thinking skills (HOTS) (Zohar, 2004). In an inquiry-based classroom, students participate in learning experiences that require them to use thinking skills by asking questions, designing, and carrying out investigations, interpreting data as evidence, creating arguments, building models, and communicating findings, to deepen their understanding of science idea using logic and evidence (Crawford, 2014). HOTS can be conceptualized as a nonalgorithmic, and self-regulating; yield multiple solutions; require the application of multiple criteria; and often involve uncertainty (Resnick, 1987). In accordance with the Benchmarks for Scientific Literacy (AAAS, 1993) and the NSESs (NRC, 1996), Zohar and Dori (2003) suggested that the thinking skills such as formulating a research question, planning experiments, controlling variables, drawing inferences, making and justifying arguments, identifying hidden assumptions, and identifying reliable sources of information, are classified as HOTS in inquiry-oriented science education. These skills are focused on cognitive activities more complex than the lower level of taxonomy; knowledge, comprehension, or application (Bloom, 1956).

Particularly, terms such as critical thinking, creative thinking, and higher-order thinking have been discussed increasingly in the science educational literature (Miri et al., 2007; Sternberg and Lubart, 1996; Zohar, 2004; Zohar and Dori, 2003). Several previous studies have recommended inquiry-based instruction as teaching foundation to promote the thinking skills (Madhuri et al., 2012; Thaiposri and Wannapiroon, 2015; Wilks, 1995), and inquiry process cannot be separated from these thinking forms (Andersen and Mila, 2017; Bailin and Battersby, 2015; Thompson, 2017). Although, many HOTS are interrelated with scientific inquiry, these concepts are difficult to define. Moreover, taking into consideration that investigating all forms of HOTS will be too complex, the number of researches has focused the study on teaching for the promotion of a particular HOTS, especially on enhancing students' critical thinking (Bailin and Battersby, 2015; Ku et al., 2014). Miri et al. (2007), for example, used the broad view of critical thinking that involves three skills such as analysis, evaluation, and inference to frame their study. In accordance with the Next Generation Science Standards (NGSS Lead States, 2013), Osborne (2014) recognized critical, reasoning, and creative thinking as core interrelated HOTS in science. As a framework of this study, the three forms of thinking have been defined as HOTS in inquiry. In relation to inquiry-based learning, the search for explanations is driven by the desire to answer the causal question - how could this has happened? At the beginning of inquiry process, creative thinking enable students to generate divergent investigable questions. Scientific reasoning enable students to pose preliminary hypotheses, hypothesis testing, evidence evaluation, and explanation of results (Dolan and Grady, 2010). The testing of ideas requires the design of investigations and the collection and analysis of data. Such questions engender the students' creative imagination, the construction of models and the production of explanatory hypotheses. When confronted by a new idea, students will evaluate scientific claims, weigh evidence, and assess alternative explanations underlying argumentation that is central to critical thinking (Driver et al., 2000).

\section{Inquiry-based science teaching}

Inquiry has been prominent in the science education reform literature for decades. As a pedagogical approach, inquiry helps students achieve science understanding "by combining scientific knowledge with reasoning and thinking skills" (NRC, 1996. p. 2). Scientific inquiry requires the use of evidence, logic, and imagination to develop explanations about the natural world (AAAS, 1993). However, Keys and Bryan (2001) stated that "inquiry is not a specific teaching method or curriculum model" (p. 632) and that "multiple modes and patterns of inquiry-based instruction are not only inevitable but also desirable because they paint a rich picture of meaningful learning in diverse situations" (p. 632). Researchers have referenced definitions of inquiry that vary by contextual consideration. Due to the absence of a clearly formulated philosophy on the nature of scientific inquiry and limitations on the scope of inquiry presented in the curriculum (AbdEl-Khalick et al., 2004), science teacher educators struggle with how to teach inquiry in their courses (Newman et al., 2004). Hence, as the framework for this study, five essential features of inquiry served as the dominant paradigm of science education: (a) Engaging in scientifically oriented questions; 
(b) giving priority to evidence; (c) formulating explanations from evidence to address scientifically oriented questions; (d) evaluating explanations in light of alternative explanations, particularly those reflecting scientific understanding; and (e) communicating and justifying proposed explanations (NRC, 2000). Inquiry as characterized by NRC has the advantage of indicating a level of scientific inquiry thinking in line with the previous research exploring inquiry levels in science curricular and learning activities (e.g., Aldahmash et al., 2016).

\section{METHODOLOGY}

A concurrent mixed methods design was applied for this study of pre-service teachers' scientific inquiry teaching practices (Creswell and Clark, 2017). The purpose of concurrent triangulation designs is to use both quantitative and qualitative data to describe the effect of the inquiry-based program on science pre-service teachers' teaching practices to promote student thinking skills. The Science Teacher Inquiry Rubric (STIR) (Beerer and Bodzin, 2004) was used quantitatively to analyze features and levels of inquiry-based science teaching in pre and end-course lesson plans designed by pre-service teachers. Data on pre-service teachers' lesson plans used in microteaching after entering the inquiry method course and self-reflections on their microteaching practices were also analyzed qualitatively to validate and expand quantitative results.

\section{Participants and Inquiry Method Course}

The participants composed of 15 pre-service teachers in a science teaching program. These two males and 13 females ranging in age from 20 to 22 years were $4^{\text {th }}$-year students enrolled in the subject of scientific thinking of a 5-year teacher enhancement program. Participation was voluntary with the option to withdraw at any point in the course of the study. They had studied curriculum, teaching methods, creation and use of technology, and assessment in prior years before entering the 1 -year professional training in their $5^{\text {th }}$ year of study.

The inquiry-based methods course described in this study was designed for a typical 15-week semester. To enhance pre-service teachers' teaching practices that promote students' thinking skills, inquiry experiences and reflection on action served as a basis for developing learning activities in the methods course. During the first class period of the course, to provide pre-service teachers' understanding of the features of inquiry, an inquiry activity was used to get them involved. The activity started with an engagement activity which led participant formulates a series of questions on how roller coasters work that they were to follow in the investigation. After that, they were asked to design, build and analyze model roller coasters they make using foam tubing and marbles (as the cars). Their preliminary explanations based on evidences were generated, and evaluated to draw conclusion.

After that, a series of inquiry-based activities were used as model lessons to introduce pre-service teachers the definition and inclusion of HOTS in inquiry process. The focus on
HOTS associated to five main phases of inquiry-based learning process, including asking questions, hypothesis generation, hypothesis testing (design of investigations and models), evidence evaluation, and communicating and justifying proposed explanations (NRC, 2000), as shown in Figure 1. The first phase, asking questions, and encourages pre-service teachers to apply creative thinking to formulate scientific questions for figuring out a scientific problem. The second phase, hypothesis generation, includes formulation of relations between variables and problems of the study. The pre-service science teachers use reasoning skills to generate hypothesis for making logic inference to the best possible explanation. The third phase, hypothesis testing, pre-service teachers collect data to test hypothesizes which they formulated. They use creative thinking to design of investigations or models to test their ideas and use reasoning skill to construct explanatory hypotheses. The critical thinking uses as basis in fourth-five phase, preservice teachers analyze and interpret data to make empirical claims and arguments, and then they will evaluate scientific claims, weigh evidence, and assess alternative explanations. A crime scene investigation activity, for example, is used as a model lesson to present the emphasis of critical thinking skills in the fourth-five phase of inquiry.

When pre-service teachers are given the responsibility of analyzing the cause of death of a victim, they formulate and select relevant and promising hypotheses, test hypothesizes by collecting evidences such as fingerprints, blood drops, hair, and draw conclusions validly and judge the validity of references.

Another key activity for the course was pre-service teachers' self-reflections on their own thinking processes that guided their investigations. Pre-service teachers reflected weekly on inquiry features and thinking skills they had used while engaged in inquiry activities. Finally, each pre-service teacher created a lesson plan to engage students' HOTS. Next, the teachers engaged in microteaching with their peers, after which they conducted self-reflections focusing on inquiry features and thinking skills they had implemented, and instructor feedback was provided.

\section{Data Collection and Analysis}

Before beginning the science methods course, pre-service teachers designed individual lesson plans that promoted learners' thinking. The lesson plans were evaluated using the STIR tool developed by Beerer and Bodzin (2004). The STIR instrument explicitly draws from the five essential features of inquiry framework. Within each of these features, a four-level (1-4) rating was used. These levels were based on the amount of initiative taken by the teacher or students in the activity. At the highest level of inquiry, students took initiative for all five essential features of the inquiry. The lowest level indicated structured or cookbook lessons involving experiments delineated in textbooks, where the method was provided and the "right answers" were identified (Bell et al., 2005). For the feature of giving priority to evidence, for example, the activity in which students tested soil properties by observing and 


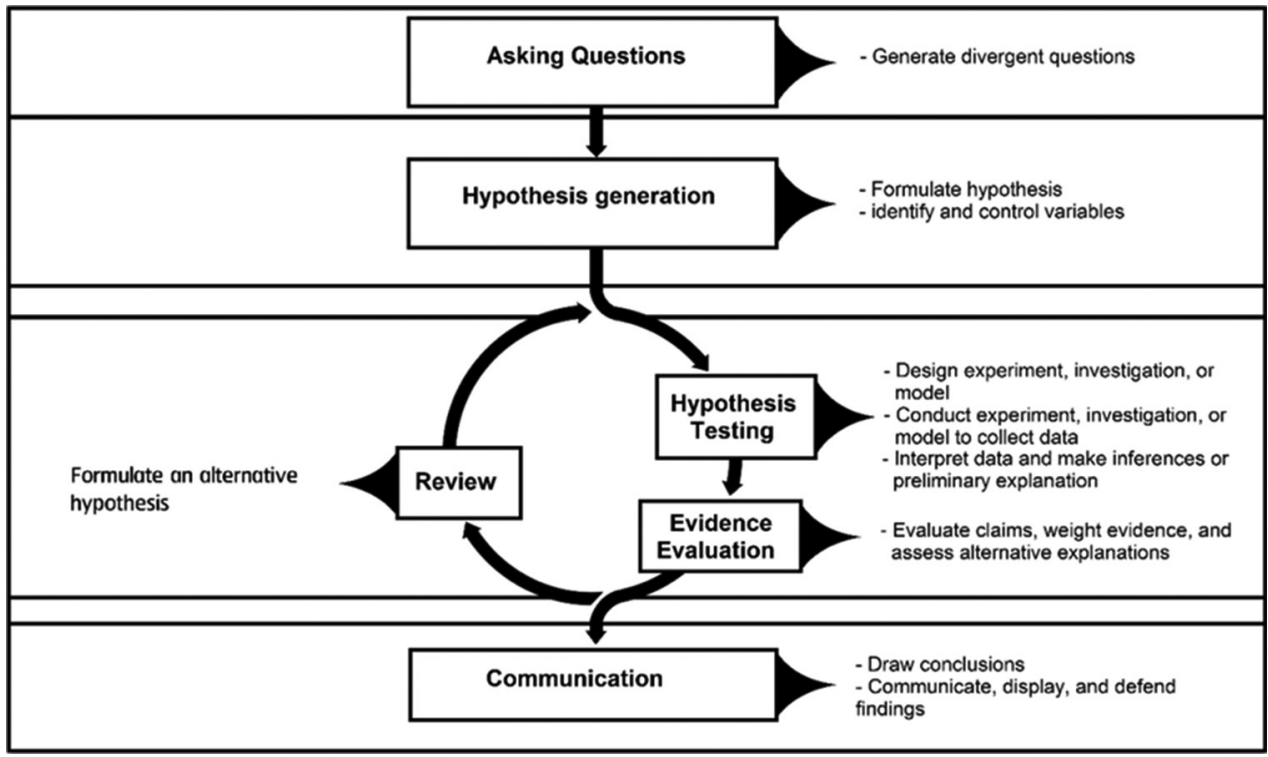

Figure 1: The inclusion of higher order skills in the process of scientific inquiry

recording soil color and texture and testing water absorption using materials and procedures provided by the teacher was ranked at level 1 . In contrast, the activity that required students to plan, design, and create a building model for areas that are tectonic for frequent earthquake occurrences was ranked at level 4. Similarly, lesson plans used in microteaching after entering the inquiry method course were evaluated using the STIR tool. These pre- and post-scores were compared to explain their progress.

The lesson plans designed by pre-service teachers were collected and analyzed across participants before and after their involvement in the science methods course. Moreover, pre-service teachers' self-reflections on their microteaching practices were also analyzed concurrently. Analysis techniques involved analytical induction (McMillan and Schumacher, 2001). Data were analyzed using coding strategies consistent with constant comparative analysis. A list of categories was developed from the conceptual framework of HOTS emerging from the five features of scientific inquiry and then used to analyze data. Lesson plans designed at the beginning of the course and data collected at the completion of the course for each participant were examined. The HOTS required for the scientific inquiry processes called for in the lesson plans were compared, coded, and descriptively labeled to represent each pre-service teacher's teaching practices. Categories were compared across individuals and continuously refined to identify and capture emergent patterns within and across individuals. Finally, comparisons were made across the semester to capture any change in pre-service teachers' teaching practices as a result of their participation in the course of this study. The findings of this study that come from a lesson plans of each pre-service teacher and self-reflection are strengthened by the analysis of the observations by the instructor. The pre-service teachers' behaviors and instructor's feedback in their microteaching were recorded and analyzed with their lesson plans.

\section{RESULTS}

While an aggregate view of the number and level of features of inquiry were interesting, it was helpful to examine the representative scientific inquiry features explicitly described and whether the features were teacher- or student-directed in pre-service science teachers' learning activities. The analyses were conducted in accordance with the frame of inquiry in the five features referred to, in short, as "question," "evidence," "explain," "connect," and "communicate." For reporting preservice teachers' teaching practices during microteaching, the term "students" referred to the other friends of the pre-service teacher who acted out as students. The results were revealed in the quantitative data, as depicted in Figure 2.

\section{Representation of Features of Scientific Inquiry and Levels of Inquiry in Pre-service Science Teachers' Learning Activities}

The inquiry-based course shifted pre-service teachers' inquiry teaching practices from placing emphasis on a process to be learned about that primarily represented only the evidence and explain features to the inclusion of the additional features of question, connect, and communicate.

Figure 2 shows that before entering the course, two of the features evidence and explain were significantly more prominent in the learning activities designed by pre-service teachers than were the other features of inquiry. These two features were found in $100 \%$ and $93 \%$ of the analyzed lesson plans, respectively. The question feature was present in $47 \%$, and the remaining inquiry features were individually present in $<25 \%$ of the learning activities. The question, connect, and communicate features were not as prominent in these 


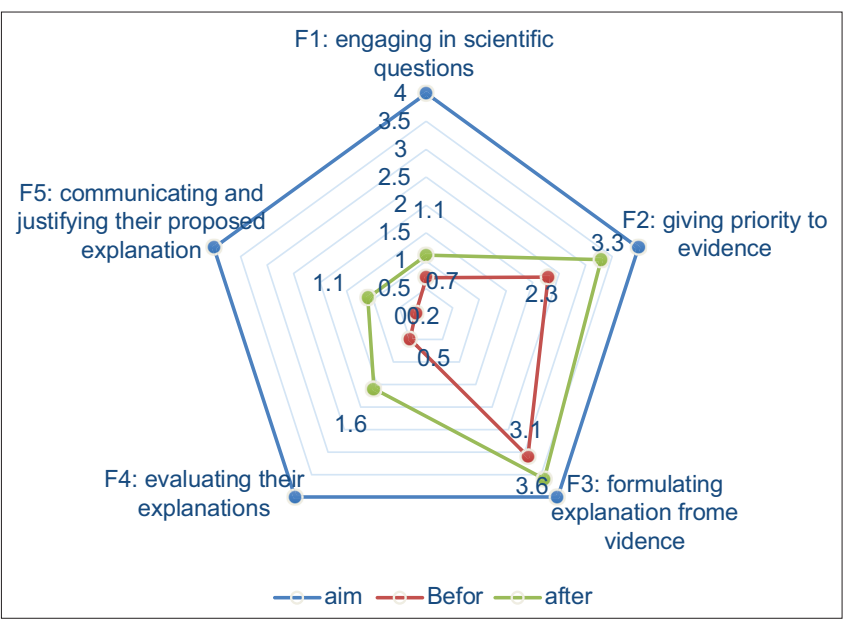

Figure 2: Means and levels for the features of scientific inquiry included in 15 pre-service teachers' designed activities

activities, which implies that the teachers viewed inquiry more as a data collection and explanation process than a process for connecting data to scientific ideas or communicating the results of investigations. The mean score of these two features (2.3 and 3.1) showed that learning activities designed by preservice teachers before enrollment in the science methods course emphasized guided-inquiry, in which students collected and analyzed evidence to support their claim based on teacherprovided direction and then constructed an explanation in response to a question posed by the teacher. For example, in a lesson on features and types of soil for Grade 4 students (students aged 9), one teacher began the lesson by asking "Do you (students) wonder how soil is formed?" "What characteristics of soil have you (students) ever seen?" and "What makes soils different from one another?" Next, students were divided into groups of 5-6 and asked to consider factors that affect soil formation and write their responses on the board. In the activity that followed, the students tested the properties of three kinds of soil by observing and recording soil color and texture and testing water absorption ability using teacherprovided materials and procedures. Then, data on the three kinds of soil were compared to identify similarities and differences. After completing the methods course, however, the analysis of teacher lesson plans showed that pre-service teachers were able to design and implement learning activities promoting thinking skills that represented all five features of inquiry. The more obvious features were evidence, connect, and communicate. Consistent with self-reflection, pre-service teachers mentioned that the design and implementation of learning activities focused on the promotion of thinking skills included all five features of inquiry. The learning activities shifted from "teacher provides guidelines for students" to "students develop their own procedures to conduct an investigation or model to figure out scientific phenomena." Allowing students to do these, students were able to use their thinking skills to construct an understanding of the natural world. In the same lesson on soil, for example, teachers launched the lesson with the questions "Why does the soil in the lawn not sink down when you step on it like it does in mangrove forests?" and "What makes each type of soil different from one another?" The students were then asked to test the properties of three kinds of soils, relying on their own procedures developed either from group discussion or by searching the internet. Moreover, data analysis and reporting were operated by students. The activity showed a higher degree of student-directedness. After scientifically oriented questions were posed, students were asked to create evidence-based explanations and connect explanations to accepted scientific concepts.

Moreover, the study's findings indicated that the inquiry method course benefited the design of activities that represented the connect and communicate inquiry features, although their mean scores were still low. The connect and communicate of the results of a scientific investigation lie in the justification of data to and with a group of peers, rather than the simple reporting of that data. before entering the course, many activities designed by pre-service teachers described presentations in which students reported the investigation data; however, there was little evidence that students justified their results and explanations with evidence. However, after completing the methods course, students were given opportunities to build and test explanatory models, compare ideas, and reach consensus. An example of such an activity was the lesson on earthquakes. The teacher introduced the lesson with a video clip about a building collapsing from an earthquake to stimulate students' questioning, which led to their investigation of how building structures should be designed in areas of frequent earthquake occurrences. Then, the students planned, designed, and created a building model using materials provided. The effectiveness of each model was tested by vibration resistance and then the models were redesigned. Finally, the teacher asked questions to open discussion about suitable structures for buildings constructed in areas with frequent earthquakes. Consistent with self-reflection, pre-service teachers reflected that a way to promote the connect and communicate inquiry features was to provide opportunities for students to justify the quality of their explanations or products, instead of judging the quality of arguments from the evidence used to support claims. In doing so, students were able to determine whether those claims were supported by credible evidence and were consistent with accepted scientific models.

\section{Types of Thinking Promoted in Inquiry Activity}

The thinking skills applied in the five key features of inquiry were analyzed by comparing data obtained from the precourse lesson plan with data from the lesson plans used in microteaching and teachers' self-reflections on their practices. The types of thinking pre-service teachers promoted that increased after participation in the methods course are summarized as follows.

\section{Asking divergent questions on a problematic situation leads students to construct explanations and design solutions.}

Findings revealed that the course encouraged pre-service teachers' teaching practices that promoted students' creative 
thinking, especially asking divergent questions that could be answered through investigation. Figure 2 showed that lesson activities that stimulated students to participate in the questioning inquiry feature increased, but most of the questions were provided by teachers. They did not encourage students to generate their own questions from their own interests and experiences. However, pre-service teachers, after participating in the science methods course, asked divergent questions on a problematic situation, leading students to construct explanations, design solutions, or develop models, and instead of asking knowledge questions that required recalling facts or basic reasoning.

Before participating in the course, pre-service teachers asked explanatory questions such as "Why?" to prompt students to recall basic reasoning using factual knowledge. For example, in a lesson on materials for Grade 3, the question "Why is each object made from a different type of material?" was posed. Answering this question required recall of basic reasoning using factual knowledge about the properties (e.g., hardness, flexibility, and solubility) of each material. Only three preservice teachers used problematic situations to encourage students to think diversely to design solutions for the problem. For example, in a lesson on natural fuel, one teacher used oil spills in the ocean and the potential contamination of beaches and sediment and serious harm to marine wildlife to stimulate students to consider "What are ways to clean up oil spills?" Students brainstormed ideas in small groups and shared their final answers with the class.

In contrast, 12 pre-service teachers, after entering the course, encouraged students' creative thinking by asking divergent questions on a problematic situation, prompting students to construct explanations, design solutions, or develop models. In addition to asking reasoning questions, such as "Why?" to elicit explanations of phenomena, open-ended questions, such as "what happened when....." and "how do you...?" were posed. These questions allowed students to generate possible hypotheses or solutions, leading to investigation. For example, in a lesson on heat transfer for Grade 7, students were to consider being the sole survivor of an airplane crash in the forest who was hungry and killed a wild boar for food. No tools or materials were available for making a fire, but a hot springs with poison vapor were located nearby. The question "How do you use the heat from the hot springs to grill the wild boar?" was posed to engage students' thinking about a solution. Students were given the opportunity to think independently, and then the agreed on answer of inserting the wild boar with a pointed material and putting it into the hot water was evaluated. Next, the focus question "What material is best for conducting heat?" was presented to frame an investigation. The following activity involved testing the heat conductivity of various materials. Students designed their own experiments to test the materials and measure the rate of heat transfer. Finally, students explained what material was best for conducting heat and why. Based on pre-service teachers' reflections, using a problematic situation with divergent questions was proven to stimulate students' engagement in an investigation that led to constructing explanations. A pre-service teacher, for example, mentioned that engaging students with a problematic situation by asking "What can we do to solve the energy crisis?" at the beginning of a lesson on alternative energy could lead to the design of diverse solutions.

\section{Thinking originally for investigation and making sense of natural phenomena by building and refining model or design}

This type of thinking involves asking questions to stimulate diverse answers and to engage students in original thinking to plan scientific investigations. Learning activities designed by pre-service teachers shifted from hands-on activities for finding results or answers to planning and carrying out investigations or constructing models to explain scientific phenomena. Most pre-service teachers, early in the course, focused learning activities on hands-on processes to find results or answers, instead of on requiring students to plan actions, including evidence collection, and to answer the question. The role of students was to follow directions. For example, in a lesson on soil, the teacher asked "What characteristics of soil have you ever seen?" and "What are the different types of soil?" Next, students conducted an experiment to determine soil properties, such as texture, color, and water-holding capacity, following teacher directions. Nevertheless, students taught by two pre-service teachers were stimulated to use their creativity to design novel inventions without questions or hypotheses posed for investigation. For example, in one lesson, a teacher asked students to invent a wind-powered car from materials provided (e.g., plastic bottles, bottle cap, bamboo skewer, drinking straws, and balloons) based on the concept of Newton's third law, after which the students presented the inventions they created. In another lesson, students were asked "Why are things capable of moving?" This led to original thinking to plan and carry out an investigation. For example, an experiment was devised in which a marble was placed on a flat surface, and then another marble was rolled on the surface to hit the first marble. The observation was made that when the first marble hit the second, it caused the second marble to move, both marbles moving in opposite directions. The force during elastic and inelastic collisions could be measured by a wireless acceleration sensor.

After participating in the course, learning activities designed by pre-service teachers shifted toward focusing on original thinking originally for a scientific investigation, especially on building and refining models or designing activities rather than performing activities following teacher direction. After the problematic situation was posed, a model was designed, tested, and redesigned to solve the problem. For example, in a lesson on earthquakes, a teacher launched the lesson with a video clip about a building collapsing from an earthquake to stimulate students' questioning, which led to an investigation onto design building structures in areas that are tectonic for frequent earthquake occurrences. Then, the students planned, designed, 
and created a building model using their imagination. Testing for vibration resistance was done to measure the effectiveness of the models, and then the models were redesigned. Finally, the teacher asked questions to prompt discussion on the features needed for building structures in areas with frequent earthquakes. Consistent with self-reflection, pre-service teachers mentioned that "when students were allowed to design building models independently, they demonstrated original thought after considering the properties of the materials being used, strengths, and vibration resistance of the building." Nevertheless, they were unable to design and implementation of activities that provided students opportunities in using original thinking to plan an investigation to identify the relation between two variables.

\section{Thinking reasonably to generate and test a hypothesis leads to causal inference and building and refining models or designs}

Research results revealed an increase in the number of pre-service teachers able to design learning activities to promote students' reasoning for causal inference-making and model building. At the beginning of the course, most pre-service teachers allowed students to find answers directly without considering relevant variables that led to planning an investigation to confirm or reject the hypothesis. Only two teachers allowed students (other pre-service teacher) to formulate hypotheses to predict the relationship between variables. However, inference-making was based on their own experiences rather than on evidence gained from an investigation. For example, in a lesson on motion aimed to answer the question "What should we do to make the object move long distances within a limited amount of time?" students were allowed to hypothesize the factors (e.g., mass, surface, and angle) affecting the distance objects moved. As another example, a teacher allowed students to generate hypotheses about materials that can absorb oil well in attempting to solve the problem of oil spills in the ocean. The activities of both teachers were followed by small group discussions, and ideas were shared based on students own experiences, rather than allowing them to design experiments to test their hypotheses and make valid inferences based on evidence. However, the remaining pre-service teachers were unable to provide opportunities for students to formulate a hypothesis to determine how two variables were related; the stated problems involved a set of variables, such as the shape of objects floating and sinking, stimuli for animal behaviors, and temperatures for changing the state of matter.

After participating in the course, seven pre-service teachers were able to design model-based reasoning lessons. Students made causal inferences and designed models or inventions to solve problems. Within this process, students generated, tested, and revised hypotheses of relevant variables to confirm or reject hypotheses. In a lesson on buoyancy, for example, one teacher referenced a ship crash to stimulate students' thinking about factors affecting an object's sinking and floating. The activity that followed involved designing a boat with maximum capacity for carrying people. The relation of variables (e.g., shape, volume, size, and type of material used) and floating was generated, tested, regenerated, and retested as a cycle during the design process. Next, students developed explanations on their model or design with supporting evidence, and then compared ideas with one another. After implementation, preservice teacher reflected that the activity promoted reasoning skills by encouraging students to generate causal explanations based on relevant factors that affect a phenomenon. Similarly, other teachers also mentioned that they encouraged students to think reasonably to generate and test a hypothesis leads to causal inferences. However, based on analysis of lesson plans, none of the pre-service teachers organized the activities that provide students opportunities to think critically to establish what to measure, how to measure different variables, how many measurements to take, and with what accuracy.

\section{Thinking critically to make a claim with supported evidence in argumentation to reach consensus on a shared explanation}

The findings showed that critical thinking used to critique possible explanations to determine whether claims were supported by credible evidence was encouraged by few pre-service teachers both before and after participating in the course. Nevertheless, teachers, after the course, engaged students' critical thinking implicitly during their interactions with one another when comparing ideas in groups during building model/design. Before participating in the course, the use of critical thinking to determine the validity of evidence and reasoning for supporting claims was ignored by pre-service teachers. Only three teachers engaged students in making claim with supported evidence and personal experience reasoning. Teachers launched the lesson with a question that arose from a situation and could be answered by searching for information from various sources, following which their findings were discussed based on the credibility of the data sources. For example, in a lesson on the theory of plate tectonic movement, a teacher asked students to make a claim about the reason a geological map from each era was different and then allowed students to find evidence to support their claim about the theory of plate tectonic movement. Their findings were shared with other students, followed by light discussion on the credibility of the data sources students used to support their claim.

After participating in the course, only three pre-service teachers allowed students to develop arguments using claims, evidence, and reasoning in supportive or controversial discussions to evaluate and refine explanations. Other pre-service teachers taught by six pre-service teachers provided learning activities that allowed for the implicit use of critical thought during interactions with one another to compare ideas in groups during building model/design, and then comparing them as a class and reaching a consensus. For example, in a lesson on air pressure, a teacher let students invent a propeller that floats in the air for as long as possible. Based on classroom 
observation, it was discovered that while designing the propeller, each group discussed possible factors, such as size, length, weight, and shape that could affect the duration of float time. Students collaborated to construct an explanatory model of what a propeller that floats for long periods of time looks like, shared their models, and engaged in argumentation from evidence to reach consensus on a shared explanation. Argumentation occurred in the classroom when multiple student ideas emerged. Students needed to compare, evaluate, and eventually reach consensus on a theory. Teacher reflected that this activity could support student thinking skills by providing them opportunities to redesign their models. Based on their own and peer careful thought, students could test the relevant factors and then combine them to design the propeller that would float the longest.

\section{DISCUSSION, CONCLUSIONS, AND IMPLICATIONS}

In this study, HOTS related to key aspects of inquiry were used as a basic framework to develop pre-service science teachers' proficiencies for teaching. The study examined both elements and levels of inquiry and types of thinking utilized by pre-service teachers. The study contributes to the literature by examining the interrelated type of HOTS in inquiry-based lessons implemented by teachers. While many studies have investigated teachers' use of inquiry-based instruction to support HOTS in broad view (Marshall and Horton, 2011) or put specific focus on a particular type of thinking skill such as critical thinking (Miri et al., 2007) and creative thinking (Thompson, 2017), few studies have provided a framework for planning and implementing science activities that include interrelated thinking skills in science (e.g., Osborne, 2014). None have specifically the relation of inquiry and these HOTS as a framework for developing pre-service science teachers' teaching practices. This framework proved a helpful model for developing science methods courses or other areas of professional development, providing the advantage of promoting higher levels, and types of HOTS related to scientific inquiry.

The study found that science method courses structured on direct inquiry experiences and reflections could enable pre-service teachers' teaching practices to promote HOTS. The participation in a series of hands-on activities that represent the relation of each type of higher order thinking to phases of inquiry process enables the pre-service teacher to conceptualize and implement activities to promote higher order thinking. However, the inquiry process benefited the design of activities that represented the promotion of interrelated between creative and reasoning thinking rather than critical thinking. The activities designed and implemented by the teachers more emphasize on using creativity to ask divergent questions on a problematic situation leads students to design of investigations or models to test their ideas, and use reasoning skills to generate hypothesis for making logic inference to the best possible explanation. Ability to include critical thinking to evaluate whether claims were supported by credible evidence to reach consensus was still difficult for pre-service teachers. Although, the previous studies argued that participation in scientific investigations helps pre-service teachers to teach by emphasizing inquiry (Anderson, 2002; Crawford, 2007), arranging activities for pre-service teachers with authentic inquiry experiences in science method courses are important (Yoon et al., 2012). In this study, most of the model lessons were content-specific and relied on standard content. The construction of alternative explanations to lead to argumentation was rare. For example, the task encourages student teachers to generate the "floating and sinking rule" of provided objects, used to represent reasoning skills. The notion of hypothesis generation, hypothesis testing for making logic inference is mentioned explicitly. However, the similar explanations about relationship between an object's volume and mass called its density were commonly used to describe why some things float and others sink. In contrast, the crime scene investigation activity- a non-specific content was used to introduce critical thinking. The activity asked student teachers to analyze the cause of death of a victim by formulating and selecting relevant and promising hypotheses, testing hypotheses, drawing valid conclusions, and judging the validity of references. Using critical thinking in evidencebased argumentation was explicitly shown in this activity. The findings are consistent with the previous research that provided authentic inquiry experiences have impact on teachers' beliefs and practices (Brown and Melear, 2006). The collaboration with scientists to provide authentic inquiry experiences for pre-service teachers through science courses has been an effort to encourage more effective inquiry instruction (Brown et al., 2002). These findings suggest that future courses for developing pre-service teachers' teaching practices to promote higher order thinking could focus on authentic science experiences.

The pre-service teachers' understanding of the NOS as a way of knowing or the values and beliefs inherent to the development of scientific knowledge (Lederman, 1999) is affected on inquiry-based teaching practices. The finding showed that most pre-service teachers focused their teaching practices on the NOS related to the product of scientific inquiry, which is scientific knowledge and modeling, instead of on the nature of science inquiry (NOSI) related to the process of scientific inquiry (Schwartz et al., 2008; Lederman et al., 2014). Lederman (1998) stated that a functional understanding of the NOS and scientific inquiry by teachers is "prerequisite to any hope of achieving the vision of science teaching and learning specified in the various reform efforts" (p. 2). The conceptual framework of the NOS, characterized as being empirically based, tentative, subjective, creative, unified, and cultural and socially embedded (Lederman et al., 2002; Schwartz et al., 2004), is large and contains many components. Furthermore, Lederman and Lederman (2012) revealed that research related to the development of teachers' knowledge 
about scientific inquiry for supporting instructional capacity is rare. Consequently, inquiry method courses designed to support inquiry teaching practices could focus on the NOSI. Six aspects of the NOSI that are accessible and relevant for students were described by Schwartz et al. (2008): Scientific questions guiding research, multiple methods of research, multiple purposes of research, justification of scientific knowledge, distinctions between data and evidence, and community of practice. Prior research reveals that effective teaching about the NOSI requires explicit/reflective attention (Lederman et al., 2013; Schwartz et al., 2004). The teacher development program/method course should be purposeful and guide learners to reflect on their experiences and relevant NOSI. Educators must provide an inquiry learning experience and then guide pre-service teachers to reflect on what they have done in light of specific NOSI aspects. Therefore, this study potentially contributes to the thinking literature by investigating the explicit-reflective instruction of the NOSI applied in the context of an inquiry course for pre-service science teachers for developing student thinking skills.

\section{ACKNOWLEDGMENT}

This work was supported by research support funds for faculty members and staff of the Faculty of Education, Kasetsart University, Thailand.

\section{REFERENCES}

AAAS. (1993). Benchmarks for Science Literacy. Oxford: Oxford University Press.

Abd-El-Khalick, F., Boujaoude, S., Duschl, R., Lederman, N.G., MamlokNaaman, R., Hofstein, A., Niaz, M., Treagust, D., \& Tuan, H.L. (2004). Inquiry in science education: International perspectives. Science Education, 88(3), 397-419.

Aldahmash, A.H., Mansour, N.S., Alshamrani, S.M., \& Almohi, S. (2016). An analysis of activities in Saudi Arabian middle school science textbooks and workbooks for the inclusion of essential features of inquiry. Research in Science Education, 46(6), 879-900.

Andersen, C., \& Mila, M.G. (2017). Scientific rEasoning during iNquiry: Teaching for Metacognition in Science Education. Leiden, Netherlands: Brill Sense. pp. 105-117.

Anderson, R.D. (2002). Reforming science teaching: What research says about inquiry. Journal of Science Teacher Education, 13(1), 1-12.

Ann Haefner, L., \& Zembal-Saul, C. (2004). Learning by doing? Prospective elementary teachers' developing understandings of scientific inquiry and science teaching and learning. International Journal of Science Education, 26(13), 1653-1674.

Bailin, S., \& Battersby, M. (2015). Teaching critical thinking as inquiry. In: Davies, M., \& Barnett, R., (Eds.), The Palgrave Handbook of Critical Thinking in Higher Education. London, United Kingdom: Palgrave Macmillan. pp. 123-138.

Beerer, K., \& Bodzin, A. (2004). Promoting Inquiry-based Science Instruction with the Science Teacher Inquiry Rubric (STIR). Nashville, TN: Association for the Education of Teachers in Science Annual International Conference.

Bell, R.L., Smetana, L., \& Binns, I. (2005). Simplifying inquiry instruction. The Science Teacher, 72(7), 30-33.

Bloom, B.S. (1956). Taxonomy of Educational Objectives: The Classification of Educational Goals. Harlow, United Kingdom: Longmans, Green.

Britner, S.L., \& Finson, K.D. (2005). Preservice teachers' reflections on their growth in an inquiry-oriented science pedagogy course. Journal of Elementary Science Education, 17(1), 39-54.

Brown, S.L., Bolton, K., Chadwell, N., \& Melear, C.T. (2002). Preservice secondary science teacher apprenticeship experience with scientists. In: Paper Presented at the Annual Meeting of Association for the Education of Teacher of Science, Charlotte, North Carolina.

Brown, S.L., \& Melear, C.T. (2006). Investigation of secondary science teachers' beliefs and practices after authentic inquiry-based experiences. Journal of Research in Science Teaching: The Official Journal of the National Association for Research in Science Teaching, 43(9), 938-962.

Crawford, B.A. (2007). Learning to teach science as inquiry in the rough and tumble of practice. Journal of Research in Science Teaching, 44(4), 613-642.

Crawford, B.A. (2014). From inquiry to scientific practices in the science classroom. In: Lederman, N.G., \& Abell, S.K., (Eds.), Handbook of Research on Science Education. Vol. 2. Abingdon, United Kingdom: Routledge. pp. 529-556.

Crawford, B.A. (2016). Supporting Teachers in Inquiry/Science Practices, Modeling, and Complex Reasoning in Science Classrooms. Southern African, Pretoria: Paper Presented at the Southern Africa Association for Research in Mathematics, Science, and Technology Education Annual Conference.

Creswell, J.W., \& Clark, V.L.P. (2017). Designing and Conducting Mixed Methods Research. Thousand Oaks, California: Sage Publications.

Dolan, E., \& Grady, J. (2010). Recognizing students' scientific reasoning: A tool for categorizing complexity of reasoning during teaching by inquiry. Journal of Science Teacher Education, 21(1), 31-55.

Driver, R., Newton, P., \& Osborne, J. (2000). Establishing the norms of scientific argumentation in classrooms. Science Education, 84(3), 287312.

Keys, C.W., \& Bryan, L.A. (2001). Co-constructing inquiry-based science with teachers: Essential research for lasting reform. Journal of Research in Science Teaching, 38, 631-645.

Kim, M., \& Chin, C. (2011). Pre-service teachers' views on practical work with inquiry orientation in textbook-oriented science classrooms. International Journal of Environmental and Science Education, 6(1), 23-37.

Ku, K.Y., Ho, I.T., Hau, K.T., \& Lai, E.C. (2014). Integrating direct and inquiry-based instruction in the teaching of critical thinking: An intervention study. Instructional Science, 42(2), 251-269.

Lederman, J.S., Lederman, N.G., Bartos, S.A., Bartels, S.L., Meyer, A.A., \& Schwartz, R.S. (2014). Meaningful assessment of learners' understandings about scientific inquiry the views about scientific inquiry (VASI) questionnaire. Journal of Research in Science Teaching, 51(1), 65-83

Lederman, N.G. (1998). The state of science education: Subject matter without content. Electronic Journal of Science Education, 3(2), 1-12.

Lederman, N.G. (1999). Teachers' understanding of the nature of science: Factors that facilitate orimpede the relationship. Journal of Research in Science Teaching, 36(8), 916-929.

Lederman, N.G., \& Lederman, J.S. (2012). Nature of scientific knowledge and scientific inquiry: Building instructional capacity through professional development. In: Fraser, B.J., Tobin, K., \& McRobbie, C.J., (Eds.), Second International Handbook of Science Education. Berlin, Germany: Springer. pp. 335-359.

Lederman, N.G., Abd-El-Khalick, F., Bell, R.L., \& Schwartz, R.S. (2002). Views of nature of science questionnaire: Toward valid and meaningful assessment of learners' conceptions of nature of science. Journal of Research in Science Teaching, 39(6), 497-521.

Lederman, N.G., Lederman, J.S., \& Antink, A. (2013). Nature of science and scientific inquiry as contexts for the learning of science and achievement of scientific literacy. International Journal of Education in Mathematics Science and Technology, 1(3), 138-147.

Lee, C.K., \& Shea, M. (2016). An analysis of pre-service elementary teachers' understanding of inquiry-based science teaching. Science Education International, 27(2), 217-237.

Madhuri, G.V., Kantamreddi, V.S.S., \& Goteti, L.N.S. (2012). Promoting higher order thinking skills using inquiry-based learning. European Journal of Engineering Education, 37(2), 117-123.

Magee, P.A., \& Flessner, R. (2012). Collaborating to improve inquiry-based teaching in elementary science and mathematics methods courses. Science Education International, 23(4), 353.

Marshall, J.C., \& Horton, R.M. (2011). The relationship of teacher- 
facilitated, inquiry-based instruction to student higher-order thinking. School Science and Mathematics, 111(3), 93-101.

McMillan J.H., \& Schumacher S. (2001). Research in Education: A conceptual introduction. $5^{\text {th }}$ ed. Harlow: Longman.

Miri, B., David, B.C., \& Uri, Z. (2007). Purposely teaching for the promotion of higher-order thinking skills: A case of critical thinking. Research in Science Education, 37(4), 353-369.

Morrison, J.A. (2014). Scientists' participation in teacher professional development: The impact on fourth to eighth grade teachers' understanding and implementation of inquiry science. International Journal of Science and Mathematics Education, 12(4), 793-816.

Newman, W.J. Jr., Abell, S.K., Hubbard, P.D., McDonald, J., Otaala, J., \& Martini, M. (2004). Dilemmas of teaching inquiry in elementary science methods. Journal of Science Teacher Education, 15(4), 257-279.

NGSS Lead States. (2013). Next Generation Science Standards: For States, by States. Washington, DC: United States National Academies Press.

NRC. (1996). National Science Education Standards. Washington, DC, United States: National Academy Press.

NRC. (2000). Inquiry and the National Science Education Standards. Washington, DC, United States: National Academy Press.

Osborne, J. (2014). Teaching critical thinking? New directions in science education. School Science Review, 352, 53-62.

Resnick, L. (1987). Education and Learning to Think. Washington, DC, United States: National Academy.

Rod Watson, J., Swain, J.R., \& McRobbie, C. (2004). Students' discussions in practical scientific inquiries. International Journal of Science Education, 26(1), 25-45.

Schwartz, R.S., Lederman, N.G., \& Crawford, B.A. (2004). Developing views of nature of science in an authentic context: An explicit approach to bridging the gap between nature of science and scientific inquiry.
Science Education, 88(4), 610-645.

Schwartz, R.S., Lederman, N.G., \& Lederman, J.S. (2008). An instrument to assess views of scientific inquiry: The VOSI Questionnaire. Baltimore, MD: Paper Presented at the International Conference of the National Association for Research in Science Teaching.

Sternberg, R.J., \& Lubart, T.I. (1996). Investing in creativity. American Psychologist, 51(7), 677-688

Thaiposri, P., \& Wannapiroon, P. (2015). Enhancing students' critical thinking skills through teaching and learning by inquiry-based learning activities using social network and cloud computing. Procedia Social and Behavioral Sciences, 174, 2137-2144.

Thompson, T. (2017). Teaching creativity through inquiry science. Gifted Child Today, 40(1), 29-42.

Wilks, S. (1995). Critical and Creative Thinking: Strategies for Classroom Inquiry. Portsmouth: Heinemann Educational Publishers.

Windschitl, M. (2003). Inquiry projects in science teacher education: What can investigative experiences reveal about teacher thinking and eventual classroom practice? Science Education, 87(1), 112-143.

Yager, R.E., \& Akcay, H. (2010). The advantages of an inquiry approach for science instruction in middle grades. School Science and Mathematics, $110(1), 5-12$.

Yoon, H.G., Joung, Y.J., \& Kim, M. (2012). The challenges of science inquiry teaching for pre-service teachers in elementary classrooms: Difficulties on and under the scene. Research in Science Education, 42(3), 589-608.

Zohar, A. (2004). Higher Order Thinking in Science Classrooms: Students' Learning and Teachers' Professional Development. Vol. 22. Berlin, Germany: Springer Science and Business Media.

Zohar, A., \& Dori, Y.J. (2003). Higher order thinking skills and lowachieving students: Are they mutually exclusive? The Journal of the Learning Sciences, 12(2), 145-181. 